\title{
Alvin Lucier's Music for Solo Performer: Experimental music beyond sonification
}

\author{
VOLKER STRAEBEL* and WILM THOBEN*, $\uparrow$ \\ *Technische Universität Berlin, Fachgebiet Audiokommunikation, Einsteinufer 17c, Sekr. E-N 8, 10578 Berlin, Germany \\ †UCLA Design | Media Arts, Broad Art Center, 240 Charles E. Young Drive, Los Angeles, CA 90095, USA \\ E-mails: volker.straebel@tu-berlin.de; me@wilmthoben.com
}

\begin{abstract}
Alvin Lucier's Music for Solo Performer (1965), often referred to as the 'brain wave piece', has become a key work of experimental music. Its setup, in which the brain waves of a solo performer are made to excite percussion instruments, has given the work a central place in the discourse on artistic sonification. However, only a small number of the authors making reference to the work seem to have studied the score, and even fewer have given thought to the score's implications for performance practice and aesthetic reflection. This paper pays detailed attention to these yet overlooked aspects, drawing on accounts of early performances as well as the authors' participation in a $\mathbf{2 0 1 2}$ performance led by the composer. We also trace the history of live-electronic equipment used for Music for Solo Performer and discuss the work's reception in sonification research.
\end{abstract}

\section{INTRODUCTION}

Alvin Lucier's Music for Solo Performer for enormously amplified brain waves and percussion (1965) is often considered an early example of artistic sonification. The image of a performer sitting motionless on stage and 'playing' an ensemble of percussion instruments by means of electrodes attached to his head has become iconic (Figure 1). However, the direct transmission of EEG data to loudspeakers that excite percussion instruments via sympathetic vibration is an illusion, an intended theatrical effect. Between data detection and sonic result lies a whole chain of decisions, operations and technical devices that may constitute the technique of sonification. The decision to deliberately conceal this chain of operations is of no little importance in creating of an image of sonification. In this paper, we want to discuss both, technique and claim, to analyse Music for Solo Performer as a landmark piece of experimental music as well as an example for the discourse in sonification research.

\section{SOURCES}

Music for Solo Performer was premiered on 5 May 1965 at the Rose Art Museum of Brandeis University in Waltham, Massachusetts. The performance was preceded by John Cage performing his $0^{\prime} 00^{\prime \prime}$ (1962); after the intermission Christian Wolff's For 1, 2, or 3
People (1964) and the premiere of Cage's Rozart Mix for 88 tape loops were presented. Alvin Lucier, who held a position as choral conductor at Brandeis, had invited Cage to do a concert and Cage insisted to have works by Wolff and Lucier performed. Out of the documented accounts about the concert and its preparation (Cage 1965; Lucier 1967b: 40-1, 1972: 22-3, 2005: 498-506, 2012a: 51-3; Lucier and Simon 1980: 69-78; Revill 1992: 210-12), a 2001 impromptu talk by Lucier is the most detailed:

I said I didn't have a piece (laughs). And there was silence on the phone. Then I said, 'Well, I am working with a brain-wave amplifier, but it doesn't work (laughter). I can't get the amplifier to work.' And he [John Cage] laughed and said, 'It doesn't matter if it doesn't work' ...

Until the night before the concert, I didn't know exactly what the piece was going to be. ... I set up 16 acousticsuspension speakers around the museum, all of them touching percussion instruments. I sat there without a mixer - we didn't have any mixers then - the brain waves went through [Edmond] Dewan's differential amplifier, then into 8 stereo hi-fi amplifiers, one after the other, in a cascade. ${ }^{1}$ There were 16 percussion instruments, including a piano, a cardboard box and a metal trash container (the speakers were simply placed inside). As the alpha [brain waves] flowed through the speakers, the instruments were physically resonated. Cage was my assistant (laughs). I asked him how long he thought the performance should be; maybe 8 or 10 minutes? He said it ought to be 40 minutes! In those days, that was a really long time for a piece of music.

So I went to bed that night. I felt really bad. I was very nervous and anxious, because I thought, 'I don't have a structure for this.' I mean, I'm a composer. I should impose some kind of structure, but then I thought, no, 


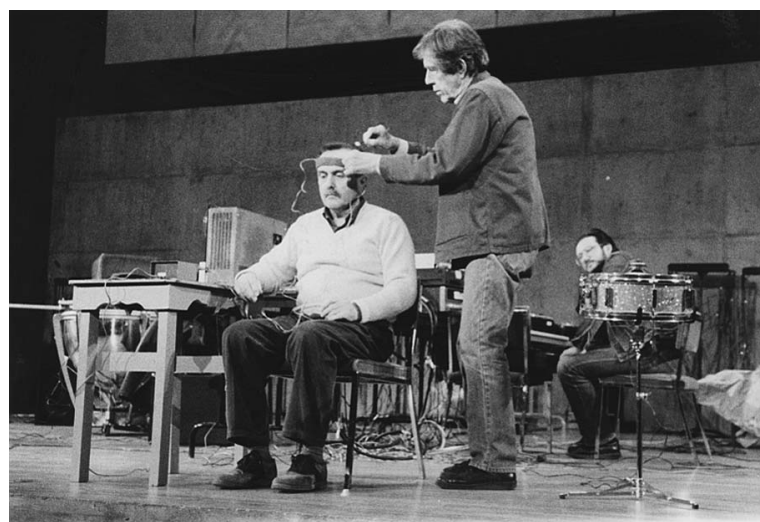

Figure 1. Alvin Lucier (soloist, left) and John Cage (assistant, right) preparing a performance of Lucier's Music for Solo Performer at the festival John Cage at Wesleyan, 1988. ( ) Special Collections \& Archives, Wesleyan University, used by permission.

brain waves are a natural phenomenon. They should just flow out, and I will trust John Cage to move the sounds from one speaker to another. (Lucier 2001: 29).

\subsection{Score}

Gordon Mumma, who, like Alvin Lucier, David Tudor and John Tilbury, served as soloist in Music for Solo Performer in the early years (Mumma 1968: 69; Simmons 1969: 342), remarked in a 1968 essay about the piece how he was surprised that 'as the musical use of elaborate and sophisticated electronic technology increases, passing works of art on to succeeding generations requires reverting to a kind of ancient oral tradition' (Mumma 1968: 69). Indeed, the verbal score of Music for Solo Performer (Figure 2) was created after the fact, and perhaps not even long before its first publication (Lucier 1980). ${ }^{2}$ In early performances the soloists relied on direct instructions from the composer and a shared understanding of live electronics performance practice and experimental music aesthetics. In Mumma's words, they had to '[learn] the work directly from the composer' (Mumma 1968: 69), and, based on that knowledge, had to find their own solutions when Lucier wasn't present (for David Tudor's 1967 performance at University of California Davis, see Tudor's 1989 interview (Tudor and Austin 1989), and

${ }^{2}$ The reprint (Lucier 2005a) combines paragraphs 3, 4, and 5 of the first publication (Lucier 1980) into one. Also, in the score's first publication the title still reads Music for Solo Performer (1965), the year of creation being part of the title. This is in accordance with other early publications, like the programme leaflet of the 1966 Stockholm performance (Music for Solo Performer, 1965 (Wiggen 1966: 3)), Lucier's early writings (Music for Solo Performer 1965 (Lucier 1967b, 1972); Music for Solo Performer (1965) (Lucier 1976)), and Gordon Mumma's accounts (Music for Solo Performer 1965 (Mumma 1968, 1975: 331)).

\section{MUSIC FOR SOLO PERFORMER (1965)}

for enormously amplified brain waves and percussion.

The alpha rhythm of the brain has a range of from 8 to $12 \mathrm{~Hz}$, and, if amplified enormously and channeled through an appropriate transducer, can be made audible. It can be blocked by visual attention with the eyes open or mental activity with the eyes closed. No part of the motor system is involved in any way. Control of the alpha consists simply of alteration of thought content-for example, a shifting back and forth from a state of visual imagery to one of relaxed resting.

Place an EEG scalp electrode on each hemisphere of the occipital, frontal, or other appropriate region of the performer's head. Attach a reference electrode to an ear, finger, or other location suitable for cutting down electrical noise. Route the signal through an appropriate amplifier and mixer to any number of amplifiers and loudspeakers directly coupled to percussion instruments, including large gongs, cymbals, tympani, metal ashcans, cardboard boxes, bass and snare drums (small loudspeakers face down on them), and to switches, sensitive to alpha, which activate one or more tape recorders upon which are stored pre-recorded, sped-up alpha. Set free and block alpha in bursts and phrases of any length, the sounds of which, as they emanate from the loudspeakers, cause the percussion instruments to vibrate sympathetically. An assistant may channel the signal to any or all of the loudspeakers in any combination at any volume, and, from time to time, engage the switches to the tape recorders. Performances may be of any length.

Experiment with electrodes on other parts of the head in an attempt to pick up other waves of different frequencies and to create stereo effects. Use alpha to activate radios, television sets, lights, alarms, and other audio-visual devices.

Design automated systems, with or without coded relays, with which the performer may perform the piece without the aid of an assistant.

Edmond Dewan, Technical Consultant

Figure 2. Alvin Lucier, Music for Solo Performer, verbal score (Lucier 1980). (c) Wesleyan University Press, used by permission.

for John Tilbury's 1969 London performance, see 2.2 below).

In 1968, Mumma mentioned a 'score' (his quotation marks) that Lucier recently had prepared, 'a kit of parts including electrodes, paste, lead-in wires, a differential amplifier and low-pass filter, and an instruction manual [that] awaits verification in the hands of future solo performers' (Mumma 1968: 68). It seems like this 'score' was merely a set of devices beyond standard sound amplification equipment but essential for the performance of Music for Solo Performer. ${ }^{3}$ As with John Cage's compositions for prepared piano where the composer held on to certain sets of preparation objects, at the time of the work's creation the understanding of what the piece essentially constitutes wasn't yet fully developed. Lucier would specify exact models and brands of equipment (Lucier 1967b: 40, 1972: 24, 1976: 60) until it became evident that the devices could be replaced by other models or even other technology that served the same purpose.

${ }^{3}$ In 1972, Lucier described more precisely: 'A performance kit for Music for Solo Performer 1965 is available on a rental basis from the composer. It includes a set of 3 scalp electrodes, 1 tube of electrode paste, 1 Cybersonics Model 301 preamplifier with extra batteries and operating instructions, 12 -channel tape of processed pre-recorded brain waves and 1 set of performance directions' (Lucier 1972: 24). 
After his performance at the Fylkingen-Festival on 21 September 1966 in Stockholm, Lucier contributed a text about Music for Solo Performer to the following year's edition of Fylkingen Bulletin International (Lucier 1967b). The first part presents basically the same information given in the published verbal score, but in the latter part, after the general statements about alpha waves in the first paragraph, Lucier changes the perspective to that of a description of the performance at the Rose Art Museum of 1965 (and the Stockholm performance of 1966). He is avoiding a score's projective imperative in favor of a report's observational past tense.

The second part of the text is entitled 'Remarks and suggestions for future performances' and consists of six numbered paragraphs that encourage the performer:

(1) to use more than two electrodes to pick up brain waves and to attempt to create stereo effects between hemispheres

(2) to use more speakers of various sizes and to use a wider variety of instruments and resonating objects ('including pianos, harps, harpsichords, drums, cymbals, sheets of glass, metals, water and so forth')

(3) to use the threshold switch in a more sophisticated way ("perhaps with relays which could activate several tape recorders in tandem, radios, machinery, television sets, lights, alarms and so forth')

(4) to operate the controls without an assistant

(5) to invent a 'more elaborate signal system' to communicate more detailed instructions to the assistant - or '[on] the other hand, instructions may be dispensed with altogether'

(6) to perform any length of time ${ }^{4}$ (Lucier 1967b: 41).

Music for Solo Performer is Lucier's first experimental music composition, and it comes as no surprise that the composer who was used to precisely notating his works (even his Action Music for Piano (1962) records the performer's movements in rather precise graphic notation (Lucier 1967a)) was hesitant to call a verbal description of a performance a score. Lucier's attitude changed as his artistic work developed during the 1960s and 1970s, and he later considered verbal notation a worthwhile approach to communicate a work's essence without restricting the performative process too much. As he recently explained in relation to his Vespers (1970): 'The score specifies a task to be accomplished, not a composer's idea of a fixed object.

\footnotetext{
${ }^{4}$ That the duration of the performance may be undetermined stands in contrast to the information given before stating that the premiere lasted about forty minutes. A review of a 1966 Boston performance describes the duration as ' 20 minutes plus' (Gelles 1966), while a review of a performance by John Tilbury at Purcell Room in London on 25 February 1969 speaks of 'nearly forty minutes' (Simmons 1969: 342).
}

One would miss so much ... by the presence of specific instructions. There would be no way to pin down the variables. Nor would I want to pin them down. They change themselves as the performance progresses' (Lucier 2012b: 254).

\subsection{An early performance}

Some remarks on John Tilbury's performance of Lucier's Music for Solo Performer at Purcell Room in London on 25 February 1969 might shed some light on the relation between score and performance before the score's 1980 publication (Lucier 1980) when the composer was not immediately involved. A reviewer reports that the "charming young leather-jacketed pianist [John Tilbury] came on again, but sat in a chair. A solicitous nurse paid attention to the rear of his skull to which two wires were attached. These were linked up to the apparatus and consequent throbs were amplified at different volumes for nearly forty minutes.' The reviewer left after twenty minutes, musing that he 'had been allowed to share in the secret musical thoughts of the performer' (Simmons 1969: 342).

While the duration falls into the aforementioned timeframe, two aspects attract attention: The notion of theatrical performance by having a nurse - probably recognisable by her uniform - attaching the electrodes at the back of the head (not the forehead), and the fact that percussion instruments are not mentioned at all. John Tilbury remembered some forty years after the performance the reason for that:

I recall that it was impressively theatrical. Akin to a surgical theatre. I sat centre-stage, I think. Casually but not shabbily attired. After a few moments a moment of drama: a female doctor came on stage, attired appropriately (professionally) in white. I think she was from the Neurology department of a London hospital. She placed the electrodes on my scalp; I can't remember exactly how she fixed them but I seem to recall that some kind of paste was involved. She probably then exited, but I can't recall exactly. I think I was alone on stage for around 40 minutes trying to achieve Samadhi (emancipation from thought). Not that far away from playing Feldman, come to think of it. There were percussion instruments positioned around the Purcell Room. I must have had an assistant or partner who dealt with this aspect of the piece. Could have been Gavin Bryars? There was little or no response from the instruments. I felt I had been inadequate to the task. And yet it was 40 minutes of real drama. The audience was expectant without knowing what to expect. In fact, nothing happened. I recall a kind of hum (throb?) which was generated somewhere, somehow, in the process, but the instruments refused to speak. I recall that the saxophonist Lou Gare, who was in the audience (and a member of AMM at the time), thought it was most compelling and loved every minute of it. But I felt, at the time, that I had failed. (Tilbury 2013). 
Tilbury can't remember 'how [he] got hold of the piece, or what it said. ... [He] did phone Alvin [Lucier] on several occasions ... for advice and suggestions' (Tilbury 2013). The missing link might have been Gavin Bryars, who indeed handled the live electronics:

I think Alvin [Lucier] gave me the pre-amplifier and filters that are needed for the performance of Music for a Solo Performer, and Bob Woolford provided all the amplification and speakers (the amps were always Lux).

For the performance John [Tilbury] decided to make it quite theatrical. We came on to the stage together and he sat in a chair as a nurse, in uniform, attached the three contacts to his scalp - one at the back of the head, the other two on top at the front. He sat perfectly still, with his eyes closed of course (as is necessary to generate the alpha rhythm). We had various resonating materials relating to each of the speakers: I'm pretty sure we had pebbles in the cones of some, there was at least one against a tam tam, and another with a snare drum and so on.

It took a long time for anything to happen - several minutes - as John [Tilbury] had to clear his mind of any visual imagery. As soon as the very first sounds happened, they stopped almost immediately as John [Tilbury] saw the speakers and their objects in his 'mind's eye', thus arresting the alpha rhythm. But eventually we managed to keep the sound going more or less continuously and I varied the distribution of the channels as we went on. The total duration of the piece was probably around 30 minutes. (Bryars 2013)

These accounts are undecided as to whether or not a written score existed in the late 1960s. In any case, just as Gordon Mumma had pointed out (1968, discussed in 2.1 above), personal communication with the composer remained crucial, and a set of electronic devices personally provided by the composer was used.

\subsection{Recordings}

Composer-supervised recordings of Music for Solo Performer provide information about the work and its performance only to a certain extent. They might be limited in duration due to the nature of the recording media (the 1982 LP versions last $13^{\prime} 30^{\prime \prime}$ or $15^{\prime}$ respectively (Lucier 1982)) or the context of their creation (the 1976 video of Music for Solo Performer in Robert Ashley's series of composer portraits Music with Roots in the Aether lasts about 28' (Ashley 2005)). Also, they might be especially prepared for the recording media, like the recordings on the 1982 LP (Lucier 1982). Here, on Side A, Lucier 'recorded and superimposed eight versions of Music for Solo Performer, overlaying pairs of Western Classical and Jazz percussion instruments, as well as a cardboard box and a metal trash can. On Side B Pauline Oliveros recorded four versions, each with a separate World Music percussion orchestra: Indian; West African; Chinese, Japanese and Korean; and Javanese' (Lucier 1982, liner notes). Only the 2009 CD release (Lucier 2009) reflects, with a length of $39^{\prime} 14^{\prime \prime}$, the premiere performance's duration.

In most of the composer-supervised recordings we can detect sound from pre-recorded and accelerated alpha waves. ${ }^{5}$ In his description of the premiere performance, Lucier states: 'In addition to the speakers, an integrated threshold switch was employed to operate a tape recorder upon which was a tape of pre-recorded brain wave sounds accelerated 5 times to a frequency of 320 cycles' (Lucier 1967b: 40; '340 cycles' in Lucier 1972: 23). The calculation of the frequency ratio is misleading; what Lucier is actually referring to is that the brain wave recordings were played back in double speed and the result was recorded, and this process was carried out five times. This way the original frequency of $10 \mathrm{~Hz}$, which is within the alpha wave range, was sped up to $320 \mathrm{~Hz}\left(10 \mathrm{~Hz}\right.$ times $\left.2^{5}=320 \mathrm{~Hz}\right)$. However, the tape sounds used on the recordings are about one octave higher. Nicolas Collins (2013) recalls 'working with a reel-to-reel tape with one channel of audio as twice as fast/high as the other. We would select one or the other to route to an ordinary (unprepared) speaker. In addition, with reel-to-reel tape recorders one had usually an option of a few different playback speeds, which would further transpose the recording by octaves. I can't be sure the tape was labeled with the "correct" speed, and occasionally the correct speed was not available for a performance anyway.'

Curiously enough, the recording of Music for Alpha Waves, Assorted Percussion, and Automated Coded Relays (Lucier 1989), a four-minute offspring from the recording session of the 1982 LP (Lucier 1982), does not seem to include any pre-recorded and accelerated alpha waves, even though the title emphasises the control mechanism Lucier mentioned in his description of the use of pre-recorded tape in Music for Solo Performer. Nicolas Collins, who is, with Jack Stang, credited as 'recording engineer' on the 1982 LP (Lucier 1982), reports that a 16-channel audio multiplexer was used that he had built and programmed for Lucier. The device was controlled by

\footnotetext{
${ }^{5}$ About $14^{\prime} 55^{\prime \prime}$ to $16^{\prime} 30^{\prime \prime}, 19^{\prime} 00^{\prime \prime}$ to $21^{\prime} 40^{\prime \prime}, 24^{\prime} 00^{\prime \prime}$ to $24^{\prime} 50^{\prime \prime}, 25^{\prime} 05^{\prime \prime}$ to $25^{\prime} 40^{\prime \prime}, 26^{\prime} 40^{\prime \prime}$ to $27^{\prime} 20^{\prime \prime}$ in (Ashley 2005: The Music of Alvin Lucier); $5^{\prime} 30^{\prime \prime}$ to $9^{\prime} 00^{\prime \prime}$ and $10^{\prime} 00^{\prime \prime}$ to $11^{\prime} 50^{\prime \prime}$ in (Lucier 1982: Side A); $6^{\prime} 00^{\prime \prime}$ to $8^{\prime} 10^{\prime \prime}, 21^{\prime} 35^{\prime \prime}$ to $23^{\prime} 30^{\prime \prime}, 25^{\prime} 55^{\prime \prime}$ to $28^{\prime} 50^{\prime \prime}, 32^{\prime} 55^{\prime \prime}$ to $35^{\prime} 50^{\prime \prime}$ in (Lucier 2009). Because beginnings and endings are often not precisely perceivable and a clear point of reference does not exist (e.g. the beginning of an LP track), timings are given in a resolution of five seconds. Pauline Oliveros's version of four superimposed recordings (Lucier 1982: Side B) is too dense to make out additional sounds from recording media.
} 


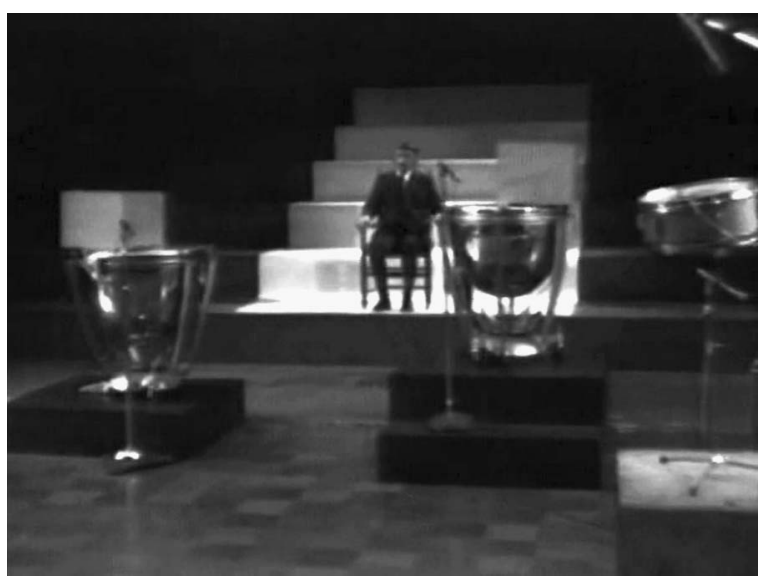

Figure 3. 1976 video of Alvin Lucier's Music for Solo Performer, from Robert Ashley's Music with Roots in the Aether (Ashley 2005: The Music of Alvin Lucier, 16 39"). (c) Performing Artservices, Inc., New York, used by permission.

a SYM 8-bit microcomputer. It replaced an earlier hardware device Collins had built for Lucier during his undergraduate studies with him at Wesleyan University in 1975 and that would emit 'a huge bang when switching the alpha'. The new device, however, served its intended purpose: 'The software looked for patterns in the alpha and channeled it among the output channels according to an algorithm. For every minute of the performance the composer/performer could preset which channels would be available to algorithm - i.e., during the first minute only select among the 4 lowest drums; for minutes - play cymbals and gongs; etc.' Nevertheless, Lucier used the device in only a few concerts, insisted on re-titling the recording for its CD release (Lucier 1989), and years later informed Collins that he had 'deleted' that version of the composition from his catalogue of compositions (Collins 2013).

While the 1982 LP versions are rather dense and almost no silences occur, the 1976 video as well as the 2009 CD release give space to less active, almost sparse sections. It seems obvious that the LP versions focus on the sounding reality of the piece and the situation of the listener who is detached from the live performance experience with its theatrical aspects. The video, on the other hand - Robert Ashley used the rather new medium's possibilities to its full extent and documented Lucier's performance in one 28-minute shot - celebrates the soloist's sitting in an armchair and his techno-musical setup of brain electrodes, long cable beams and loudspeakers attached to various percussion instruments (Figure 3). The visual atmosphere is so intense that the actual sound is obviously not the sole focus of the video. Still, as Ashley points out today, the aesthetic decision to not edit brings the video itself into the realm of

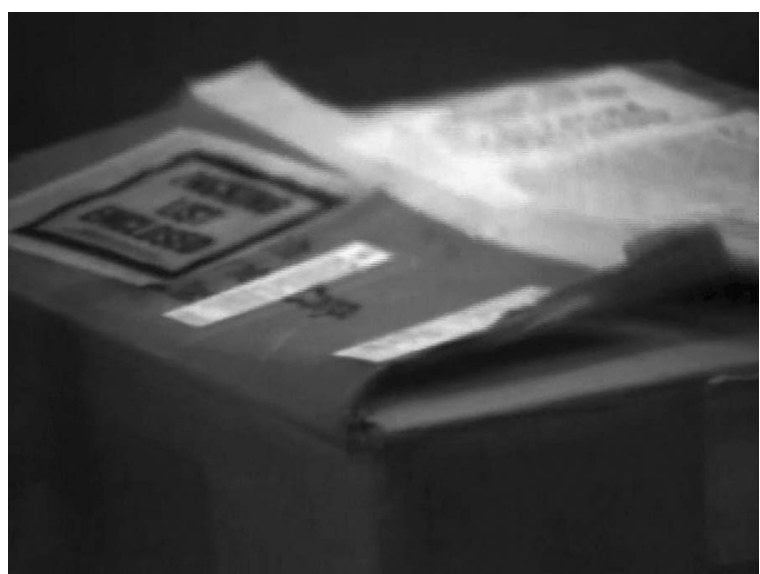

Figure 4. 1976 video of Alvin Lucier's Music for Solo Performer, from Robert Ashley's Music with Roots in the Aether (Ashley 2005: The Music of Alvin Lucier, 20'22'). (c) Performing Artservices, Inc., New York, used by permission.

music, avoiding the distanced notion of music documentary. ${ }^{6}$

Unlike in any other composer-supervised recording, the piece is allowed to start slowly while the performer slips into alpha state. Actually, much time is given to the preparation of the performance, and the camera observes closely how an assistant (probably Robert Ashley (Ashley 2013)) fixes the electrodes to Lucier's head. It takes no less than five minutes for the first sound to appear. When the camera then slowly zooms out and starts wandering among the instruments, the lack of connection between recorded image and sound becomes apparent. The camera pans while the stereo field remains steady. And as much as the camera seems to scan the setup to witness sound production, at just two instances do we actually see an instrument vibrate: a reflection of light on the skin of a bass drum indicates the vibration of the reflecting surface, and at some point the lid of a cardboard box flaps eagerly (Ashley 2005: $11^{\prime} 50^{\prime \prime}$ and $20^{\prime} 10^{\prime \prime}$, Figure 4).

\section{SIGNALS}

If one is about to analyse Music for Solo Performer in the context of sonification techniques, one needs to spend special attention to the nature of the signals observed and the procedures of their detection and processing. We focus here first on the nature of the brain waves and the amplification devices used in Music for Solo Performer, while questions of loudspeakers and their modification are discussed further down in connection with a 2012 Berlin performance.

${ }^{6}$ I've never liked the editing of music I see on TV. It's not "music." It's "about" music' (Ashley 2013). 


\subsection{Alpha waves}

Music for Solo Performer is exclusively based on particular brain waves called alpha waves, alpha rhythms or alpha synchronisation. This signal is used to excite loudspeakers attached to percussion instruments. Alpha waves are sinusoid-like neurological oscillations caused by rhythmical neurological activity in the brain. They vary heavily in frequency and typically fluctuate between 8 and $13 \mathrm{~Hz}$ (see, e.g., Shaw 2003: 4).

It is traditionally assumed that alpha synchronisation occurs when no information is processed in certain areas of the brain. Consequently it was believed that putting the mind into a state of rest could enable a person to produce alpha waves. The absence of sensory information was one of the explanations for the so-called closing eye phenomenon. For most people it is possible to enhance the amplitude of these waves dramatically simply by their closing their eyes. Opening them again during a present alpha cycle, on the other hand, is often called blocking. Recent studies, however, show that this is not entirely true. Blocking does not always occur and it is assumed that alpha areas of the brain just split up in asynchronously pulsing areas (Shaw 2003: 6).

Electroencephalography (EEG) is the favoured method to measure alpha waves in a non-invasive way suitable for musical performance. Electrodes have to be placed on the scalp to record electrical activity of the brain. The smallest possible number of electrodes necessary is three, all of them placed on the forehead: one on each hemisphere of the brain and one in the middle as a reference to the resting potential of the brain. The reference electrode can also be placed on the performer's wrist to ensure the measurement of a voltage decoupled from the brain activity. After the two voltages has been acquired, the difference between the two has to be calculated and amplified to accurately detect the brain activity. This can be achieved by using a differential amplifier, where the reference electrode represents the resting potential of the human body and the sum of all variations of the other electrodes in relation to the reference constitute the brain activity. To determine the frequency band of the brain signals, spectral processing has to be performed. Since the advance of digital equipment, measurements have become more precise due to sophisticated signal analysis algorithms. For medical purposes and more accurate spatial resolution, usually 10 to 20 electrodes or a geodesic setup is used (Miranda 2010: 156). Generally, the sum of all brain activity is measured.

\subsection{Devices}

The technology used by Lucier for performing Music for Solo Performer is based on a simple neurological
EEG measurement device. As described above, three silver electrodes, a high-gain, low-noise differential amplifier and a steep-band or low-pass filter capable of filtering out unwanted harmonics or neighbouring brainwaves are required.

For the initial experiments at Brandeis University with physicist Edmond Dewan ${ }^{7}$ two Tektronix Type 122 pre-amplifiers with a built-in band pass filter and an additional band pass filter (a device custom built by the United Transformer Corporation and a Krohn-Hite $330 \mathrm{M}$ filter) were used to obtain the alpha signal (Lucier 1967b: 40, 1972: 22-23, 1976: $60) .{ }^{8}$ The three electrodes were placed on the forehead of the performer and fixed with a headband. The Tektronix pre-amplifier had a maximum gain range of $\sim 30 \mathrm{~dB}$, so a second one had to be wired in series to achieve enough amplification to boost the signal to a sufficiently high voltage range.

Both differential pre-amplifiers were employed with the reference electrode as a ground signal to amplify the difference between both hemispheres of the brain. Lucier worked with this setup at the premiere and at least one other performance of the piece (Lucier 1967b). This equipment, originally built as measurement devices, seems to have been the first choice for early performances because it was available and tested together with Edmond Dewan.

To simplify the electronics and to provide a portable device more suitable for touring, Gordon Mumma and William Ribbens constructed the Cybersonics Differential Amplifier Low Pass Filter, named after their enterprise Cybersonics, which operated in Ann Arbor, Michigan. The device, presented as early as November 1966, contains a differential pre-amplifier with a gain of $40 \mathrm{~dB}$ at an input voltage of $10-25 \mu \mathrm{V}$ and a fourth-order low pass filter with a cutoff frequency of $14 \mathrm{~Hz}$ (Mumma 1968; $15 \mathrm{~Hz}$ according to Lucier 1972: 23). ${ }^{9}$ The oscillograph

${ }^{7}$ For a detailed account on Edmond Dewan's role in the creation of Music for Solo Performer and his scientific background see Kahn (2010, 2013: 85-90), as well as Lucier (1976: 60).

${ }^{8}$ The lowest possible cut-off frequency of the built-in filter in the Tektronix 122 pre-amplifier is $\sim 50 \mathrm{~Hz}$, hence the additional filter. The Krohn-Hite $330 \mathrm{M}$ filter had an attenuation of $12 \mathrm{~dB} /$ octave. Lucier misspelled the company's name in both papers where he mentions this device (Lucier 1967b, 1976). The correct name is 'Krohn-Hite' instead of 'Kronhite'. In his 1972 contribution to the yearbook of the Guildhall School of Music \& Drama in London, which is largely based on his Fylkingen article (Lucier 1967b), Lucier, for the only time, mentions a band pass filter that had been custom built by the United Transformer Corporation. According to this account, the device had been used for the premier at Brandeis University and was replaced in a New York performance in November 1966, and therefore might have been used at the Fylkingen Festival in September that year (Lucier 1972: 22-3, see also footnote 9).

${ }^{9}$ In 1972, Lucier described in detail: 'At the Lincoln Centre Library Auditorium on November 7, 1966, a Cybersonics Model 301 preamplifier with a built-in low pass filter set at 15 cycles per second was used, supplanting both Tektronix preamplifiers and United Transformer Corporation bandpass [sic] filter. This custommade 


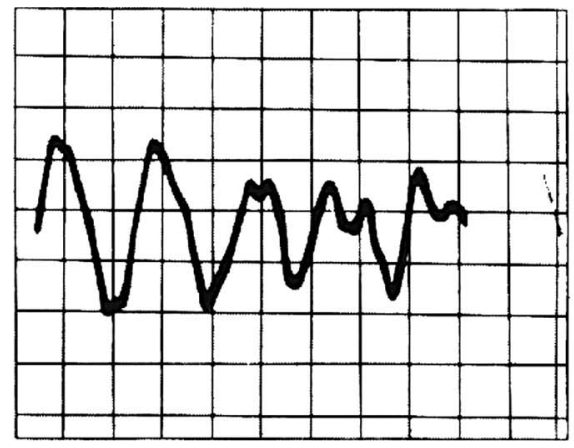

Oscilloscope tracings of amplifier oulput before filtering ( 1 voll per Abscissa Division and 50 milliseconds per Ordinate Division).

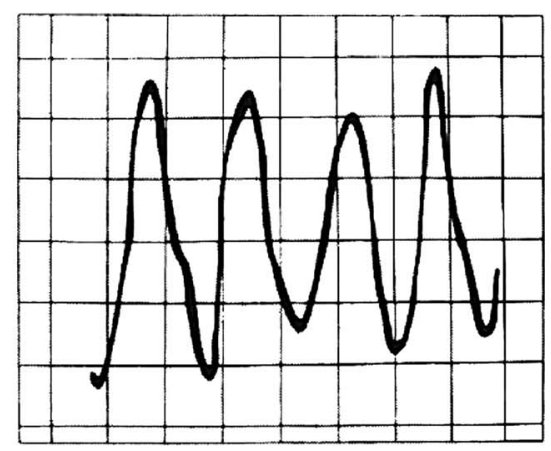

Oscilloscope tracings of amplifier output after filtering ( 1 volt per Abscissa Division and 50 milliseconds per Ordinate Division).

Figure 5. Oscilloscope tracings of amplifier output before and after Cybersonics Differential Amplifier Low Pass Filter (Mumma 1968: 68). (c) University of California Press, used by permission.

of the filtered and amplified output shows that most frequencies above $14 \mathrm{~Hz}$ are erased (Figure 5). The signal shown here is a very short excerpt of a longer sequence. Alpha waves are usually produced in bursts, and therefore they have a decaying amplitude envelope. This results in a decrescendo roll of rather steady frequency that excites the percussion instruments.

John David Fullemann, a student of Lucier and founder of Magic Boxes Co, started to work on his own device for amplifying alpha waves in 1974, which he named Alpha Amp I. Fullemann built the device for experimentation on activating LED-lights with brainwaves. Alpha Amp I led to the development of Alpha Amp II in 1975, which was then used for performance (Figure 6). Lucier also purchased one of these amplifiers for Music for Solo Performer. Some improvements were made in regard to the version built by Mumma and Ribbens. Fullemann didn't refer to the Cybersonics amp but invented a similar design. The filter stages were realised with operational amplifiers instead of transistors to decouple the filter stages from each other. Furthermore, the cutoff frequency was pushed to $20 \mathrm{~Hz}$. A headphone output was added, including a limiter stage and a passive volume control to monitor the appearance of alpha waves. Because of the massive amplification of $\sim 60 \mathrm{~dB}$ and the following limiter stage the alpha signal would result in a clicking sound (Fullemann 2013b). Fullemann revised this amplifier in 1999 and built version III. The revisions applied to this version include an additional active band pass stage after the fourth-order low-pass filter (Fullemann 2013a).

\footnotetext{
(F'note continued)

[sic] preamplifier which is much smaller and lighter in weight than the Tektronix preamplifiers and which operates on 2 miniature 15-volt batteries instead of the heavy Tektronix Type 125 Power Supply, proved to be much more convenient for performance purposes' (Lucier 1972: 23).
}

It becomes apparent that it is not defined how to measure alpha waves to perform Music for Solo Performer. The choice of the cutoff frequency and the steepness of the filters determine the sound of the loudspeakers clapping against the instruments.

If we applied modern digital measurement techniques to Music for Solo Performer - in other words, algorithmic pattern detection - the events detected in the occurring bursts would manifest more sparsely. In contrast, filtering the signal doesn't necessarily mean the resulting signal would consist exclusively of alpha bursts. Rather, almost every signal which is recorded by the electrodes, especially noise and interference, will produce output after filter stages, and therefore produce sound on the percussion instruments. Hence the design of the measurement equipment has a tremendous effect on the sonic result. ${ }^{10}$

\section{PERFORMANCE}

To get an inside perspective of the performance practice of Music for Solo Performer, the authors participated in a performance on 23 March 2012 at Haus der Berliner Festspiele during the course of MaerzMusik Berlin. Alvin Lucier performed the soloist's part, while Hauke Harder, Nicolas Collins, Volker Straebel and Wilm Thoben assisted. Nicolas Collins had studied with Alvin Lucier in the 1970s and supervised the electronic part of Music for Solo Performer numerous times, among them the 1976 video and the 1982 LP recordings. Hauke Harder has been realising installations and performances by Lucier since 1995, including Music for Solo Performer,

${ }^{10}$ In a version of Music for Solo Performer realised by Sukandar Kartadinata and Steffi Weismann (2009, Berlin), Kartadinata applied algorithms for actual detection of alpha bursts instead of just routing the filtered signal. The signal was much cleaner and less dense (see Eitel 2012). 


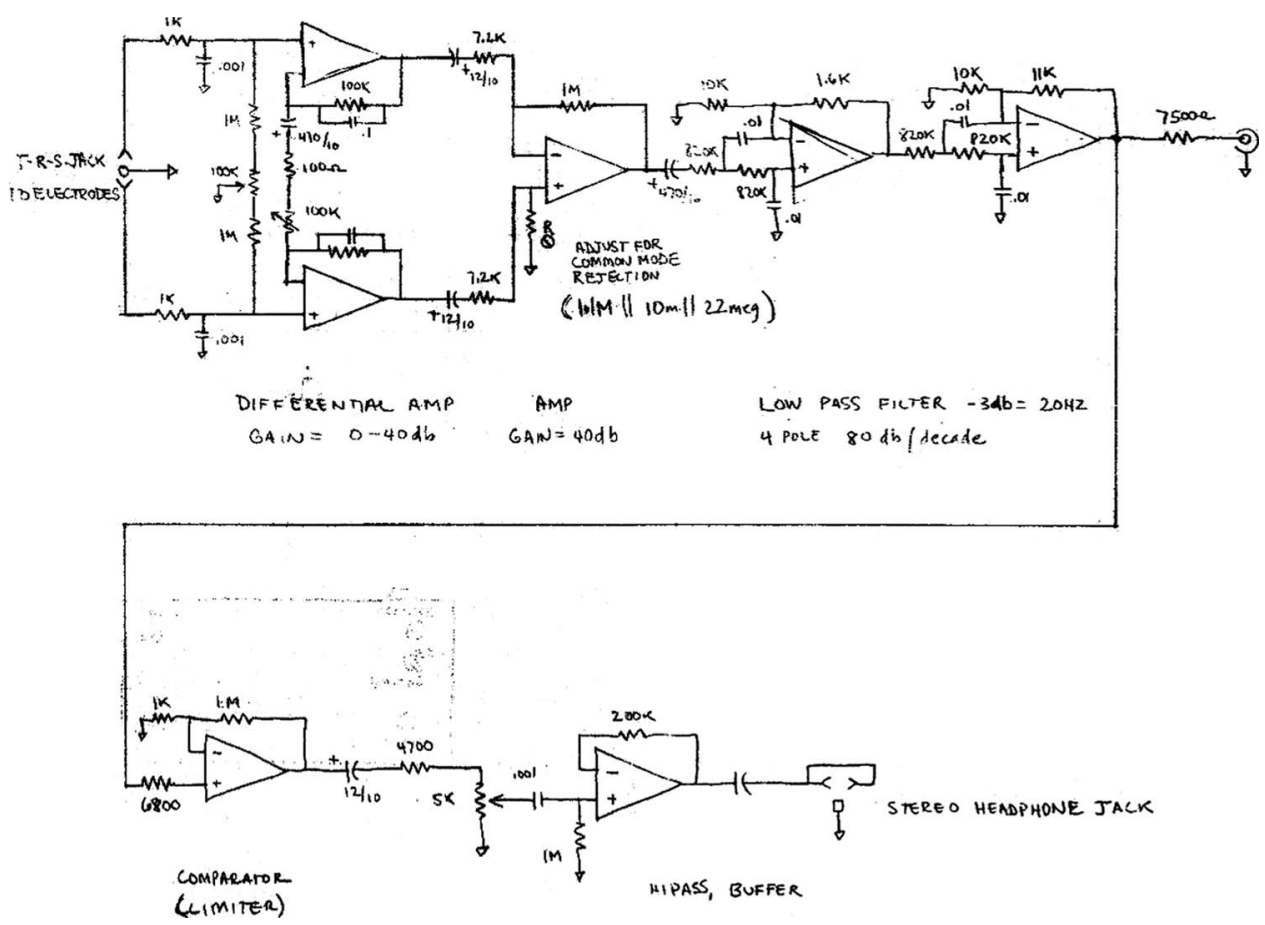

Figure 6. John David Fullemann’s Alpha Amp II (1975). ๔ John David Fullemann, used by permission.

which he did both as Lucier's assistant and as solo performer.

\subsection{Choice of instruments}

The reference for performing the piece was the score and the following list of instruments provided by the composer (Lucier 2012c):

- 1 large mixer, 16 outputs

- 16 high-quality speakers, at least $12^{\prime \prime}$ diameter

- 2 bass drums

- 2 snare drums

- 2 timpani

- 2 cymbals

- 2 triangles

- 1 tambourine

- 1 large tam tam

- 1 small gong

- 1 grand piano

- 1 cardboard box large enough to contain a speaker

- 1 metal trash can large enough to contain a speaker

- $1 \mathrm{CD}$ player.

The list, which roughly matches the choice of instruments suggested in the score (Lucier 2005a), seems to reflect personal preference as the score leaves the choice of instruments and other devices quite open to the performer. Lucier entrusted Hauke Harder and Nicolas Collins to make decisions on the choice of instruments, speakers and preparation in the manner of Lucier's performance practice of this piece. It was agreed not to use a piano because of practical reasons and to prepare smaller speakers in addition to a few $12^{\prime \prime}$ devices.

Since the performance took place in a traditional stage and seated audience setting at Haus der Berliner Festspiele, we decided to place the performer midstage and the percussion instruments in a symmetrical setup:

\begin{tabular}{ll}
\hline Stage right & Stage left \\
Large bass drum & Large bass drum \\
Cymbal & Cymbal \\
Snare drum & Snare drum \\
Small timpani & Large timpani \\
Tambourine & Small bell \\
Triangle & Triangle \\
Tam tam & Large gong \\
Cardboard box & Metal trash can \\
\hline
\end{tabular}

During the preparation the possibility of placing the instruments amidst the audience was discussed an arrangement suggested by a flow-chart diagram (Mumma 1968: 68; Lucier 1972: 24) and applied quite often in preceding performances (Harder 2012). At Haus der Berliner Festspiele, this was impossible due to the architecture and safety regulations of the space.

Additionally, a CD with pre-recorded alpha waves was played back using the stereo speaker system of the venue. The alpha waves were transposed into an audible range. 


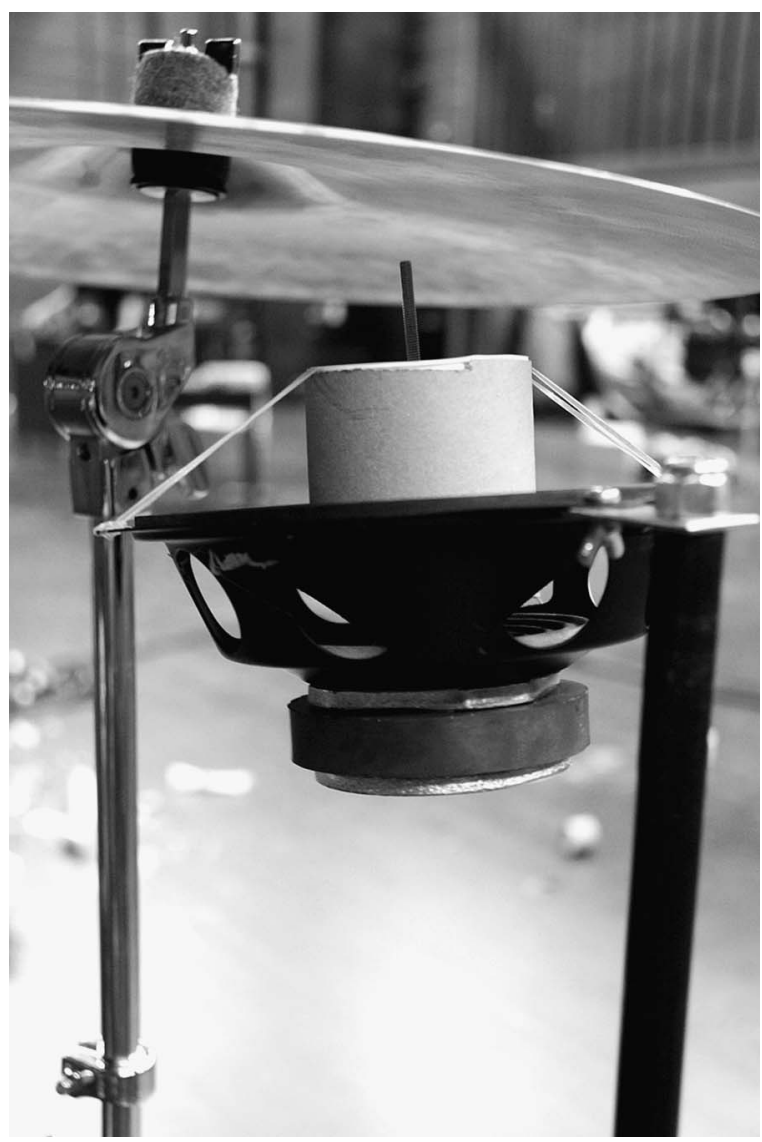

Figure 7. Prepared loudspeaker for Alvin Lucier's Music for Solo Performer, MaerzMusik, 23 March 2012, Haus der Berliner Festspiele. Photo: Giuliano Obici. (c) Giuliano Obici, used by permission.

\subsection{Speaker preparation}

Generally, there seem to be two different approaches on how to activate the resonance of the instruments. Lucier suggests using large $12^{\prime \prime}$ speakers placed on or directly in front of the instruments. Ideally, the movement of the membrane should make an instrument resonate without even touching it, but this is rarely possible. Lucier favours cone-type speakers above horn-type speakers since 'the air pressure from the cone excursions will cause the grill cloth to bump in reaction to the bursts of alpha. This bumping effect is an efficient means for resonating these instruments. The composer has found that the KLH Model 4 loudspeaker is fine for this purpose' (Lucier 1972: 24).

In another technique employed in several performances of the piece done by other performers, solenoids or prepared speakers are used to activate the instruments. On the 1982 LP recording (Lucier 1982), Collins used solenoids to play metalophones. Later he would add cork to the speaker cones to get a more mallet-like sound (Collins 2013). Harder started preparing small speakers with different material for his performances of Music for Solo Performer in 2007 and has continued using this technique (Harder 2013). For the Berlin performance, we decided to mount several 7-9" speakers on microphone stands and prepared them with small spherical-shaped objects like wood, cork, rubber, plastic or bare metal screws. Similar to Harder's technique, a small cardboard tube with a plastic cap was fixed onto the membrane with rubber bands (Figure 7). Depending on which instrument was to be excited, an appropriate material was chosen: in other words, a screw for the gong or a wooden ball for the cymbals. During setup instruments were tested one by one and adjustments were made. Usually the distance, material and position would be changed according to the personal sonic preferences of the participants. Most of the decisions were made before the composer joined the rehearsal. When he did, Lucier just commented and adjusted a few speakers himself. He chose to abandon a few of the preparations in favour of letting the bare membrane almost touch the drumhead of the timpani. The sound of flapping rubber on the timpani enabled us to produce more low-frequency content and less dominant transients.

\subsection{Formal organisation}

The form and length of the piece are not determined by the score, but it seems like Lucier has established a repeating framework for deciding how the piece is going to be performed.

Nicolas Collins and Hauke Harder were each operating eight instruments on eight faders at the mixing desk on the opposite side of the hall. Each assistant played the instruments on one side of the stage.

After the initial adjustments of the individual speakers had been completed, Lucier gave both assistants instructions on which instruments to activate at the beginning and which at the end of the piece. Furthermore it was decided that a climax in terms of density and loudness should happen in the second half of the piece. This loose improvisatory framework was used for a first run-through of the piece. During that run-through the composer would intervene when he liked or disliked what the assistants did. Other decisions made about the formal architecture were to have the gong almost as the only activated instrument for nearly five minutes at some point in the performance or the moment when the recorded and transposed alpha waves were to be played back on the regular speaker system of the hall. These were memorised and repeated in the next run-through and the performance.

Reconsidering the above-mentioned observations we see that the assistants play a crucial role in how the performance of the piece comes into being. The choice of instruments, the speaker setup and 
preparation, as well as parts of the formal organisation are decided upon and played, in large part, by the non-stage performers.

\section{SITUATING 'MUSIC FOR SOLO PERFORMER'}

The analysis of the score of Lucier's Music for Solo Performer, its performance practice and the technology involved have revealed a far more complex situation than the direct transformation of alpha signals into resonating percussion sounds. However, it is this image of the direct translation of brain activity into sound that gives reason for the work's fame and its perception in sonification research.

Over the years, the composer seems to have taken different perspectives on this issue. In 1971 he emphasised the musical decisions he was making: 'I learned that by varying both short bursts and longer sustained phrases of alpha plus making musical decisions as to the placement of loudspeakers, choice of resonant instruments or objects, volume control, channeling and mixing, I was able to get a wide variety of sonorities as well as retain the natural physical quality that seemed asked for by the sound source itself' (Lucier 1976: 61).

Later, Lucier withdrew from the concept of making artistic decisions in terms of musical form and sound production: 'In making Music for Solo Performer (1965), I had to learn to give up performing to make the performance happen. By allowing alpha to flow naturally from mind to space without intermediate processing, it was possible to create a music without compositional manipulation or purposeful performance' (Siegmeister, Lucier, and Lee 1979: 287). No wonder that in the 1976 video the assistant remains invisible. $^{11} \mathrm{We}$ only see his hands when in the beginning he attaches the electrodes to Lucier's head.

On the other hand, Lucier explained that he 'didn't want to show mind control ... Discovery is what I like, not control. I'm not a policeman. I always thought of splicing alpha waves, or cutting them up in a studio ... a being a brain surgeon - and I'm not a brain surgeon. So I completely eschewed that form ... and let that alpha just flow out, and the composition was then how to deploy those speakers, what instruments to use' (Lucier and Grimes 1986: 59), quoted in (Dewar 2009: 163). The role of the assistant remained a crucial, yet precarious one, as Collins reports: 'When I assisted he [Lucier] never spoke of

\footnotetext{
${ }^{11}$ Robert Ashley explained, 'I didn't show the mixing board or Nic[olas] Collins because it didn't seem right for the piece. In most cases [of the performances presented in Ashley's Music with Roots in the Aether (Ashley 2005)] the "mixing" is done by one of the performers; when the "mixing" is actively shaping the piece, which I think is not the case with Nic[olas Collins] in the Lucier' (Ashley 2013).
}

trying to shape the piece with his alpha "performance", but made it clear that the form of the concert was really in the hands of the assistant - hence the sometimes awkward to and fro before and after rehearsals and concerts' (Collins 2013).

\subsection{Music in sonification discourse}

Neither the role of the assistant, who controls the flow of the alpha signal to loudspeakers and percussion instruments, nor the very fact that musical decisions are made during the work's performance are mentioned in most writings that refer to Music for Solo Performer as an early example of artistic sonification (Rosenboom 1997: 10; Schoon and Dombois 2009: 2; Kahn 2010, 2013; Miranda 2010: 157-8; Grond and Berger 2011: 391; Mullen, Warp and Jansch 2011: 469; Grond and Hermann 2012: 216). Just a few scholars address the impact of the technology involved (Mumma 1968; Kahn 2010, 2013; Pickering 2010: 85), and only musically informed authors address the role of the assistant (Mumma 1968; Dewar 2009: 160; Rogalsky 2010: 135).

Already in one the founding texts of the sonification discourse, 'An Introduction to Auditory Display' by Gregory Kramer (1994), a close connection between sonification and music is made, right at the time when sonification was about to be established as a tool for research and a field of study. Kramer uses a motto by Sufi teacher Hazrat Inayat Khan (1882-1927) from his Mysticism of Sound and Music - 'in the realm of music the wise can interpret the secret and nature of the working of the whole universe' (Khan 1996: 6) - but replaces, without mentioning the change, 'music' with 'sound', thereby broadening the perspective considerably (cf. Straebel 2010: 292). In the aftermath, the International Community for Auditory Display (ICAD) has established a strong tradition of artistic sonification (of often questionable artistic quality), and only recently have scholars addressed the distinction of scientific and artistic sonification more thoroughly (Sterne and Akiyama 2012: 547-53; Supper 2012: 252-61) or critically (Vickers and Hogg 2006; Hermann 2008).

While arguing about different approaches to the definition of sonification and its connection to music, these authors usually don't question their understanding of what music is. Grond and Hermann (2012) state that 'we can speak of sonification when sound is used as a medium that represents more than just itself. In other words, sound becomes sonification when it can claim to possess explanatory powers; when it is neither solely music nor serves as mere illustration' (213). But what does it mean for sound to be 'solely music'? It seems that the authors set the concept of absolute music as a self-evident definition, thereby rejecting those concepts where 
music articulates entities beyond its sounding reality, may they be traditions of the art form, connotations of music history and theory, programmes or narratives, and so forth.

\subsection{Music beyond the audible}

Where Grond and Hermann (2012) argue that 'data inspired music ... cannot be reduced to music' (216), we claim that conceptual music cannot be reduced to sonification. The reception of Music for Solo Performer in the sonification community focuses almost exclusively on the aspect of signal production, but little thought is given to the performative aspect of the work, the explicitly musical decisions made during preparation and performance, or the role of the assistant. On the contrary, scholars have felt the urge to stress that '[in] Music for Solo Performer data are not used to make brain activity understandable but rather to emphasize the nature of thoughts and mental processes' (Grond and Hermann 2012: 216). For our understanding, even this is asking too much. Why would Lucier address the "nature of thoughts and mental processes' by using alpha waves to play a percussion piece?

The composer who has deliberately created the aura of a solo work by '[giving up] performing to make the performance happen' (Siegmeister et al. 1979: 287) is not to blame for an ill-informed interpretation, since giving (or not giving) secondary information about the piece is part of his artistic activity. The degree to which the work of art appears enigmatic is suggested by the artist. Music encompasses much more than mere sound. Its context, the aspects of its presentation and performance are an integral part of its very existence.

'You see, one of the inaccuracies of the title is that it's not really for solo performer. You need someone to run the amplifiers, to pan the sounds around, to turn on one loudspeaker and then turn on another, and I've always, except once in Stockholm, ${ }^{12}$ done it with another player, an assistant' (Lucier and Simon 2005: 52). The automation of this process, suggested by the composer in the score, never became part of Lucier's performance practice, but has been realised by other performers in recent years. Instead, the performance of Music for Solo Performer is a subtle play of hidden communication between soloist and assistant. This ensures the quality of the work on the level of musical integrity in terms of musical form (development, contrast, structure, etc.) and sonic surface (interesting sounds, diversity of sounds and

\footnotetext{
${ }^{12}$ Lucier is referring to his performance at Tekniska Museet, Stockholm, 21 September 1966, during the course of the festival Fylkingen: Visions of the Present (see Wiggen 1966; Lucier 1967b, 1972).
}

rhythms, etc.) as well as on the level of performance with its creation of the image of a solo performer controlling the sounds by the mere activity of his thinking.

\section{CONCLUSION}

Alvin Lucier's Music for Solo Performer is a work of experimental music that can be reduced to neither its method of sound production nor its sonic reality. Our analysis of the score, the technical devices used by the composer and his peers, and the composer's performance practice have given emphasise to the musical aspects at work. Music for Solo Performer is by no means a scientific setup where brain waves are automatically transformed into percussion sounds, but an artistic situation that asks for musically sensitive performers and assistants. The iconic image of a soloist performing motionlessly and relying only on brain waves to control percussion instruments is an artistic creation by the composer, not the technical reality of the piece. If Music for Solo Performer makes reference to sonification, it does so by establishing a framework of aesthetic reception beyond mere sensual perception. Therefore, in this case sonification needs to be understood as a result of artistic production, not as its means.

\section{Acknowledgements}

We would like to thank Alvin Lucier, Nicolas Collins and Hauke Harder for allowing us to join them in the concert performance of Music for Solo Performer at Haus der Berliner Festspiele, 23 March 2012 during the course of the festival MaerzMusik, as well as its artistic director Matthias Osterwold for the opportunity. We also thank Robert Ashley, Gavin Bryars, Nicolas Collins, John David Fullemann, Hauke Harder, Sukandar Kartadinata, David Revill and John Tilbury for generously sharing their recollections and thoughts.

\section{REFERENCES}

Ashley, R. 2005. Music with Roots in the Aether [1976]. New York: Lovely Music DVD7701-7, 7 DVDs.

Ashley, R. 2013. Email to Volker Straebel, 26 August 2013. Bryars, G. 2013. Email to Volker Straebel, 10 September 2013.

Cage, J. 1965. Correspondence and Notes re Rozart Mix for Magnetic Tape. New York: Henmar Press, score.

Collins, N. 2013. Email to Volker Straebel, 22 August 2013.

Dewar, A.R. 2009. Handmade Sounds: The Sonic Arts Union and American Technoculture, $\mathrm{PhD}$ thesis. Wesleyan University, Middletown, CT.

Eitel, V. 2012. The Empress of Sound: 5 Soli für/von Alvin Lucier. In MAP. Media/Archive/Performance, 3 (April 2012). http://www.perfomap.de/map3/kapitel1/ the-empress-of-sound (accessed 14 August 2013). 
Fullemann, J.D. 2013a. Email to Wilm Thoben, 3 January 2013.

Fullemann, J.D. 2013b. Email to Wilm Thoben, 4 September 2013.

Gelles, G. 1966. Electronic Concert Not Very Amusing. Boston Globe, 27 February, 26.

Grond, F. and Berger, J. 2011. Parameter Mapping Sonification. In T. Hermann, A. Hunt and J.G. Neuhoff (eds.) The Sonification Handbook. Berlin: Logos, 363-97.

Grond, F. and Hermann, T. 2012. Aesthetic Strategies in Sonification. AI \& Society 27(2) (May): 213-22.

Harder, H. 2012. Personal communication to Wilm Thoben, March 2012.

Harder, H. 2013. Email and personal communication to Volker Straebel, 30 August 2013.

Hermann, T. 2008. Taxonomy and Definitions for Sonification and Auditory Display. Proceedings of the 14th International Conference on Auditory Display. Paris, France 24-27 June.

Kahn, D. 2010. Alvin Lucier, Edmund Dewan und 'Music for Solo Performer'. In D. Gethmann (ed.) Klangmaschinen zwischen Experiment und Medientechnik. Bielefeld: Transcript, 211-29.

Kahn, D. 2013. Earth Sound Earth Signal: Energies and Earth Magnitude in the Arts. Berkely, CA: University of California Press.

Khan, H.I. 1996. The Mysticism of Sound and Music. Boston: Shambhala.

Kramer, G. 1994. An Introduction to Auditory Display. In G. Kramer (ed.) Auditory Display: Sonification, Audification, and Auditory Interfaces. Sante Fe Institute Studies in the Sciences of Complexity. Proceedings 18. Reading, MA: Addison-Wesley, 1-77.

Lucier, A. 1967a. Action Music for Piano, Book I, 1962. Don Mills, ON: BMI Canada, score.

Lucier, A. 1967b. Musik för solist/Music for Solo Performer. Fylkingen Bulletin: International Edition. Art and Technology II 2: 16-7/40-1.

Lucier, A. 1972. Music for Solo Performer 1965. In Review 1972. London: Guildhall School of Music \& Drama, $22-4$.

Lucier, A. 1976. Statement on: Music for Solo Performer [1971]. In D. Rosenboom (ed.) Biofeedback and the Arts: Results of Early Experiments. Vancouver, ON: Aesthetic Research Center of Canada, 60-1.

Lucier, A. 1980. Music for Solo Performer (1965) for Enormously Amplified Brain Waves and Percussion (1965), score. In Chambers: Scores by Alvin Lucier. Interviews with the composer by Douglas Simon. Middletown, CT: Wesleyan University Press, 67.

Lucier, A. 1982. Music for Solo Performer. New York: Lovely Music VR 1014, LP.

Lucier, A. 1989. Music for Alpha Waves, Assorted Percussion, and Automated Coded Relays [1965/1982]. In N. Collins (ed.) Imaginary Landscapes: New Electronic Music. New York: Elektra/Nonesuch 9 79235-2, CD.

Lucier, A. 2001. Seminar. In D. Eibenová, M. Perry and J. Novak (eds.) Ostrava Days 2001: New Music Institute and Festival. Ostrava: Ostrava Center for New Music, $27-38$.

Lucier, A. 2005a. Music for Solo Performer for Enormously Amplified Brain Waves and Percussion (1965).
In Reflections: Interviews, Scores, Writings 1965-1994/ Reflexionen: Interviews, Notationen, Texte 1965-1994. 2nd edn. Cologne: MusikTexte, 300-1.

Lucier, A. 2005b. Notes in the Margins: Collaborations with John Cage [1988]. In Reflections: Interviews, Scores, Writings 1965-1994/Reflexionen: Interviews, Notationen, Texte 1965-1994. 2nd edn. Cologne: MusikTexte, 498-511. Originally published: programme book 'John Cage at Wesleyan', 25 February 1988.

Lucier, A. 2009. Music for Solo Performer. In Alvin Lucier: Sferics/Music for Solo Performer. New York: Lovely Music LCD 5013, CD.

Lucier, A. 2012a. Music 109: Notes on Experimental Music. Middletown, CT: Wesleyan University Press.

Lucier, A. 2012b. Notes on Verbal Notation [2010]. In J. Lely and J. Saunders (eds.) Word Events: Perspectives on Verbal Notation. London: Continuum, 253-4.

Lucier, A. 2012c. Email to Volker Straebel, 29 January 2012.

Lucier, A. and Grimes, E. 1986. Interview. [6 June 1986 Middletown, CT]: Oral History of American Music, Yale University.

Lucier, A. and Simon, D. 1980. Chambers: Scores by Alvin Lucier. Interviews with the composer by Douglas Simon. Middletown, CT: Wesleyan University Press.

Lucier, A. and Simon, D. 2005. '... to let alpha be itself.' Music for Solo Performer [1980]. Interview, in Reflections: Interviews, Scores, Writings 1965-1994/Reflexionen: Interviews, Notationen, Texte 1965-1994. 2nd edn. Cologne: MusikTexte, 46-59. Originally published: Lucier and Simon: Chambers, 1980

Miranda, E.R. 2010. Plymouth Brain-Computer Music Interfacing Project: From EEG Audio Mixers to Composition Informed by Cognitive Neuroscience. International Journal of Arts and Technology 3(2/3): 154-76.

Mullen, T., Warp, R. and Jansch, A. 2011. Minding the (Transatlantic) Gap: An Internet-Enabled Acoustic Brain-Computer Music Interface. Paper presented at International Conference on New Interfaces for Musical Expression (NIME), Oslo. http://www.nime2011.org/ proceedings (accessed 29 January 2013).

Mumma, G. 1968. Alvin Lucier's 'Music for Solo Performer' Source: Music of the Avant-Garde 2: 68-9. Reprinted: L. Austin and D. Kahn (eds.) Source: Music of the Avant-Garde, 1966-73. Berkeley: University of California Press, 2011, 79-81.

Mumma, G. 1975. Live-Electronic Music. In J.A. Appleton and R.C. Perera (eds.) The Development and Practice of Electronic Music. Englewood Cliffs, NJ: Prentice Hall, 286-35.

Pickering, A. 2010. The Cybernetic Brain: Sketches of Another Future. Chicago: University of Chicago Press.

Revill, D. 1992. The Roaring Silence. John Cage: A Life. New York: Arcade.

Rogalsky, M.R. 2010. 'Nature' as an Organising Principle: Approaches to Chance and the Natural in the Work of John Cage, David Tudor and Alvin Lucier. Organised Sound 15(2): 133-36.

Rosenboom, D. 1997. Extended Musical Interface with the Human Nervous System. Assessment and Prospectus [1990]. Leonardo Monograph Series. San Francisco: International Society for the Arts, Sciences and Technology (ISAST). 
Schoon, A. and Dombois, F. 2009. Sonification in Music. Paper presented at 15th International Conference on Auditory Display, Copenhagen, 1-2 May. http:// www.icad.org/Proceedings/2009/SchoonDombois2009.pdf (accessed 6 January 2010).

Shaw, J.C. 2003. The Brain's Alpha Rhythms and the Mind: A Review of Classical and Modern Studies of the Alpha Rhythm Component of the Electroencephalogram with Commentaries on Associated Neuroscience and Neuropsychology. Amsterdam: Elsevier.

Siegmeister, E., Lucier, A. and Lee, M. 1979. Three Points of View [conversation]. Musical Quarterly 65(2) (April): 281-95.

Simmons, D. 1969. London Music. Musical Opinion 1099(92) (April): 342-4.

Sterne, J. and Akiyama, M. 2012. The Recording That Never Wanted to Be Heard and Other Stories of Sonification. In T. Pinch and K. Bijsterveld (eds.) The Oxford Handbook of Sound Studies. Oxford: Oxford University Press, 544-60.

Straebel, V. 2010. The Sonification Metaphor in Instrumental Music and Sonification's Romantic Implications. Proceedings of the 16th International Conference on
Auditory Display. Washington, DC: ICAD, 287-94. http://www.icad.org/icad2010/icad2010.pdf.

Supper, A. 2012. The Search for the 'Killer Application': Drawing the Boudries around the Sonification of Scientific Data. in T. Pinch and K. Bijsterveld (eds.) The Oxford Handbook of Sound Studies. Oxford: Oxford University Press, 249-70.

Tilbury, J. 2013. Email to Volker Straebel, 3 September 2013.

Tudor, D. and Austin, L. 1989. A Conversation. April 3, 1989, Denton, Texas. http://davidtudor.org/Articles/ austin.html (accessed 30 January 2013).

Vickers, P. and Hogg, B. 2006. Sonification Abstraite/ Sonification Concrète: An 'Aesthetic Perspective Space' for Classifying Auditory Displays in the Ars Musica Domain. ICAD 2006: The 12th Meeting of the International Conference on Auditory Display. London: Queen Mary, University of London. http://dev.icad.org/ Proceedings/2006/VickersHogg2006.pdf (accessed Sep 2, 2009).

Wiggen, K. (ed.) 1966. Fylkingen: Visions of the Present. Stockholm, program Tekniska Museet, Teknorama, 19-25 September 1966. 